\title{
Assessment of the Radiological Inventory for the Reactor at Kori NPP Using In-Situ Measurement Technology In-Situ 측정법을 이용한 고리 원자로 방사선원항 평가
}

Hyun Chul Jeong* and Sung Yeop Jeong

GODO TECH Co. Ltd., Rm 746 ITECO, 150 Jojeong-daero, Hanam-si, Gyeonggi-do, Korea

정현철*, 정성엽

(주)고도기술, 경기도 하남시 조정대로 150 ITECO 746호

(Received June 9, 2014 / Revised June 24, 2014 / Approved June 30, 2014)

\begin{abstract}
After the expiration of operating license of a plant, all infrastructures within the plant must be safely dismantled to the point that it no longer requires measures for radiation protection. Despite the fact that Kori 1 and Wolsong 1 are close to the expiration of their operating license, sufficient technologies for radiological characterization, decontamination and dismantling is still under development. The purpose of this study is to develop one of methods for radiological inventory assessment on measuring object by using direct measure of large component with In-Situ measurement technique. Radiological inventory was assessed by analyzing nuclide using portable gamma spectroscopy without dismantling reactor head, and the result of direct measurement was supplemented by performing indirect measurement. Radiochemical analysis were performed on surface contamination samples as well. During the study, radiological inventory of reactor vessel calculated expanding the result. Based on the result and the radioactivity variation of each radionuclides time frame for decommissioning can be decided. Thus, it is expected that during the decommissioning of plants, the result of this study will contribute to the reduction of radiation exposure to workers.
\end{abstract}

Keywords: Decommissioning, Radiological Inventory, In-Situ Object Counting System, Reactor Head, Direct measurement

원전 해체 시 원자력설비는 안전하게 해체되어야 한다. 고리 1 호기나 월성 1 호기와 같은 노후화된 원전의 경우 곧 원전 해 체를 계획하고 있는 대상 원전이지만, 이 원전들의 가동 중단 후 해체 시 선원항 평가 기준, 제염 및 해체 기술 등의 독자적 인 국내 기술 확보는 미흡한 실정이다. 본 연구의 목적은 원전 선원항 평가 기술 중 하나로 In-Situ 기법을 이용하여 대형 원 전 기기를 직접 측정하여 측정대상체에 대한 선원항 평가방법을 개발하는 것이다. 원자로 헤드를 별도의 해체 없이 이동형 감마핵종분석기를 이용하여 직접 측정법으로 분석하고 간접 측정을 병행하여 측정 결과를 보완하였다. 그리고, 표면오염시 료는 방사화학분석을 수행하였다. 분석 결과를 확장하여 원자로의 핵종 재고량을 계산하였다. 본 연구 결과를 토대로 각 핵 종별 방사능량 변화에 따라 해체 시점을 결정할 수 있으며, 원전 해체 시 작업자의 피폭 저감에 도움이 될 것으로 기대한다.

중심단어: 제염 해체, 방사선원항, 이동형 감마핵종분석기, 원자로 헤드, 직접 측정

*Corresponding Author.

Hyun Chul Jeong, GODO TECH Co. Ltd., E-mail: tanglley@godo-tech.com Tel: +82-70-7510-2001 


\section{1. 서 론}

운전 수명이 종료된 원자력설비를 안전하게 처리, 처분 하는 마지막 과정은 해체이다. 이미 원자력 선진국에서는 오 래 전부터 국가적 차원으로 해체 관련 기술에 관련하여 상당 한 기술력을 축적한 상태이다. 국내의 경우, 원전의 가동 중 단 후 원전 해체 시 선원항 평가 기술, 제염 및 해체 기술, 해 체 관련 안전성 확보를 위한 기술 등의 필요성이 공감되어 현 재 관련 기술의 연구 및 개발을 서두르고 있다.

본 연구의 목적은 원전 주요 기기에 대한 선원항 평가 의 한 가지 방법으로써, In-Situ 기법을 이용하여 대형 원전 기기를 직접 측정하는 선원항 평가방법을 개발하는데 있다. 본 평가를 위해 이동형 감마선 핵종분석기(ISOCS: In-Situ Object Counting System, Canberra Industries Inc.)를 이용 하여 체적오염에 대하여 측정대상체를 직접 측정하여 분석 하고, 표면오염 시료를 채취하여 방사화학분석을 수행하여 각 결과를 합산하여 선원항을 평가하였다.

과거 대형 원전 기기를 측정할 경우, 크러드(Crud) 시 료채취를 통한 간접적인 측정만이 가능하였지만, 현재에는 ISOCS를 이용하여 직접적인 측정이 가능하다. 이러한 기술 적 이유는 측정대상체를 모델링하여 피대상체에 대한 검출 기의 효율을 예측할 수 있었기 때문에 가능하다. 뿐만 아니 라 측정대상체를 효과적으로 측정하기 위한 차폐체 및 조리 개 등의 효과도 모델링 과정에서 검출기의 효율로 보상할 수 있기 때문에 그 정확도가 향상되었다.

본 연구에서는 원자로 Head에 대하여 방사화 특성을 분 석하고, 선원항 측정을 위한 측정전략을 수립하였다. 특히 대 상체의 오염 형태를 분석하여 최적의 측정방법을 결정하였 고, 각 측정방법에 따라 절차를 수립한 후 선원항 평가를 수행 하였다. 또한 원자로 헤드 측정 결과를 확장하여 최종 목표인 원자로의 선원항 평가를 완료하였으며, 평가 결과는 타 기관 의 Code 분석 결과와 비교하여 측정의 유효성을 검증하였다.

\section{2. 본론}

\section{1 검출시스템의 선택}

현재의 In-Situ 기법을 이용한 분석 장비는 Inspector
Table 1. Comparison of measurement equipments

\begin{tabular}{|c|c|c|c|}
\hline & $\mathrm{CZT}$ & Gamma Camera & ISOCS \\
\hline $\begin{array}{l}\text { Measurement } \\
\text { object }\end{array}$ & $\begin{array}{l}\text { - Small detector } \\
\text { - Minimal parts }\end{array}$ & $\begin{array}{l}\text { - Small } \\
\text { components } \\
\text { (pipe, wall, etc..) }\end{array}$ & $\begin{array}{l}\text { - All components } \\
\text { (any size and } \\
\text { shape) }\end{array}$ \\
\hline $\begin{array}{l}\text { Measurement } \\
\text { range } \\
\text { (Dose rate) } \\
\end{array}$ & $\begin{array}{l}\text { - Adjustable } \\
\text { (replace the } \\
\text { probe) }\end{array}$ & $\begin{array}{c}\text { - Available } \\
\text { (picture) }\end{array}$ & $\begin{array}{l}\text { - Adjustable } \\
\text { (distance control, } \\
\text { shielding) }\end{array}$ \\
\hline $\begin{array}{c}\text { Nuclide } \\
\text { identification }\end{array}$ & $\begin{array}{l}\text { - Available } \\
\text { (spectrum, } \\
\text { software) }\end{array}$ & - Unavailable & $\begin{array}{l}\text { - Available } \\
\text { (spectrum, } \\
\text { software) }\end{array}$ \\
\hline $\begin{array}{l}\text { Contaminated area } \\
\text { discrimination }\end{array}$ & $\begin{array}{l}\text { - Available } \\
\text { (Internal GM } \\
\text { Detector) }\end{array}$ & $\begin{array}{c}\text { - Available } \\
\text { (picture) }\end{array}$ & - Unavailable \\
\hline $\begin{array}{l}\text { Quantitative } \\
\text { analysis }\end{array}$ & $\begin{array}{l}\text { - Relative ratio of } \\
\text { radionuclides }\end{array}$ & - Unavailable & - Available \\
\hline
\end{tabular}

$\mathrm{CZT}, \mathrm{LaBr}_{3}$, Gamma Camera, ISOCS 등이 존재하며 이중 최 적의 원자로 헤드 측정장비를 선정하기 위해 각 검출기의 특 징을 Table 1 과 같이 비교하였다. 이 중 $\mathrm{LaBr}_{3}$ 검출기는 높 은 효율로 인하여 고방사성 물질로 예상되는 원자로 헤드 측 정에는 적합하지 않기 때문에 제외하였다.

Inspector CZT의 경우, 고 선량 부위의 측정이 가능하고 핵종 판별이 가능하지만 국소부위만을 평가하며 핵종 판별 및 핵종별 상대적 농도비를 판정할 수 있다. 따라서 대상체 의 핵종별 방사능에 대한 정량평가를 수행해야하는 본 연구 에는 적합하지 않다[1].

Gamma Camera의 경우 오염부위 확인 면에서는 사진과 같은 시각적 자료를 제공하기 때문에 오염부위 인지력은 가 장 우수하지만, 핵종 판별 및 방사능 정량평가는 수행할 수 없기 때문에 본 목적에 부합하지 못한다[2].

ISOCS의 경우 측정대상체의 크기에 상관없이 핵종 및 방사능 정량평가가 가능하고 휴대 및 이동이 용이하다. 뿐 만 아니라 차폐체를 이용하여 고선량 지역에도 설치가 가능 하다는 이점이 있기 때문에 본 연구에 최적의 장비로 판단 하였다[3].

국내외 방사능 측정기술을 조사한 결과 원자로 헤드 측 정을 위한 최적의 방법은 Gamma Camera를 이용하여 오염 부위를 판별하고 ISOCS를 이용하여 측정대상체를 직접 측 정하여 핵종분석을 수행한 다음, 최대 오염부위의 샘플링 시 료를 가공하여 전 알파, 베타, 감마핵종에 대한 분석을 수 행하여 직·간접측정법을 상호 비교하는 것이다[4][7]. 현재 
Gamma Camera는 활용할 수 없어 ISOCS만을 이용하여 선원항 평가를 수행하였다.

\section{2 원자로 헤드 측정 계획}

원자로 헤드의 방사성 오염은 중성자에 의한 체적오염과 계통수에 의한 접수면의 표면오염으로 구성된다. 이 중 표면 오염은 알파, 베타, 감마핵종에 의한 오염이 발생하지만 체 적오염은 원자로 헤드 모체 자체가 차폐 역할을 하기 때문에 감마핵종이 주요 평가대상 핵종이다.

측정방법은 체적오염의 경우 ISOCS를 이용하여 원자로 헤드를 직접 측정하여 감마핵종분석을 수행하고, 표면오염 의 경우 접수면 내부의 표면을 연마 채취한 후 알파, 베타, 감마핵종분석을 수행하였다.

\subsection{1 체적오염 측정 계획}

체적오염의 경우, Fig. 1과 같이 수직방방에서 기하학 적 측정구조가 다른 3 가지 측정구조를 각각 측정 및 검출 기 효율을 모델링하여 상호 비교하고, Fig. 2와 같이 수평 방향에서 하나의 측정구조에 대하여 검출기 효율을 예측하 고 대칭인 3 개 지점의 측정결과에 동시에 적용하여 분석결 과를 상호 비교함으로써, 원자로 헤드의 선원항 평가를 수 행하였다.

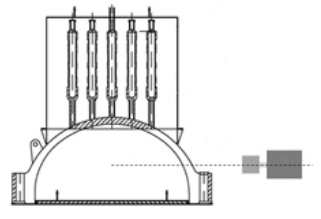

G1(0 degree)

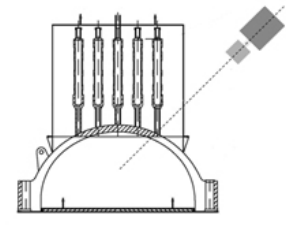

G2(45 degree)

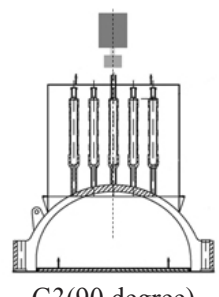

G3(90 degree)
Fig. 1. Measurement position(Vertical direction).

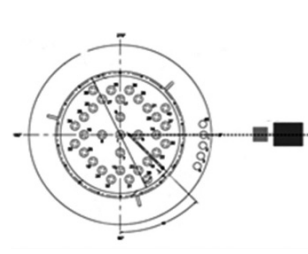

G1(0 degree)

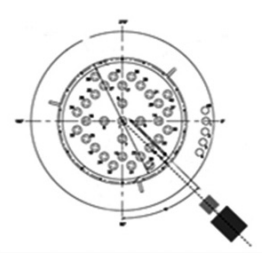

G2(45 degree)

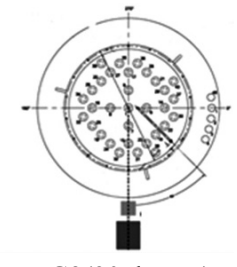

G3(90 degree)
Fig. 2. Measurement position(Horizontal direction).
ISOCS의 계산한 효율을 이용하여 핵종분석을 수행하는 경우 반드시 계산 효율에 대한 유효성 검증절차가 필요하다. 본 연구에서는 앞서 서술한 바와 같이 1 차 유효성 검증 방법 뿐만 아니라 Fig. 3과 같이 원자로 헤드에서 시편을 채취하 여 Charcoal Filter 형태로 용융 가공하여 핵종분석을 실시함 으로써 직접 및 간접측정을 상호 비교하는 2 차 유효성 검증 도 수행하였다.

2차 유효성 검증을 위한 대표 시료로써 원자로 헤드 관 통관(CRDM)을 선택한 이유는 표면선량률 측정결과 원자로 내외면의 차이가 매우 크며 내면에서 높은 결과를 나타내었 다. 반면 관통관에서 내외면의 차이가 유사하며, 원자로 내 면의 선량과 유사한 선량률이 측정되었다. 때문에 시료채취 가 용이한 관통관에서 채취하였으며 원자로 모재와 가장 가 까운 지점 3 개를 절단하여 채취하였다.

\subsection{2 표면오염 측정 계획}

표면오염 분석을 위해 Fig. 4 와 같이 원자로 헤드 내면 3 지점(대칭위치)에서 초경을 이용하여 정해진 면적을 연마하 여 시료를 채취하였다.

시료 채취는 원자로 헤드 표면이 계통수에 의해 30 년 이 상 장기간 오염이 되었기 때문에 균일하게 오염되었다고 판 단하여 대칭구조로 채취하였다. 채취한 시료는 한국원자력

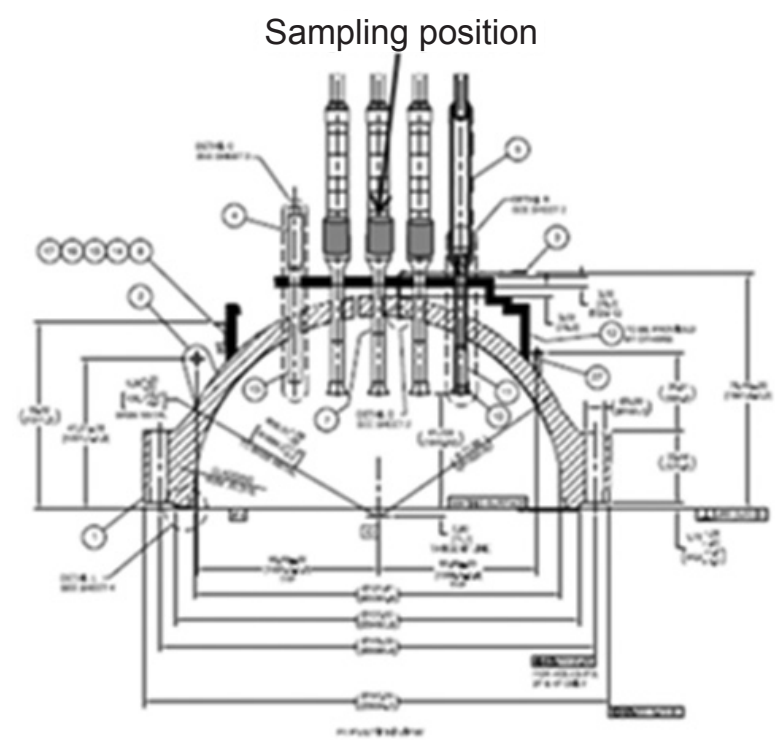

Fig. 3. Sampling position for $2^{\text {nd }}$ measurement effectiveness verification. 


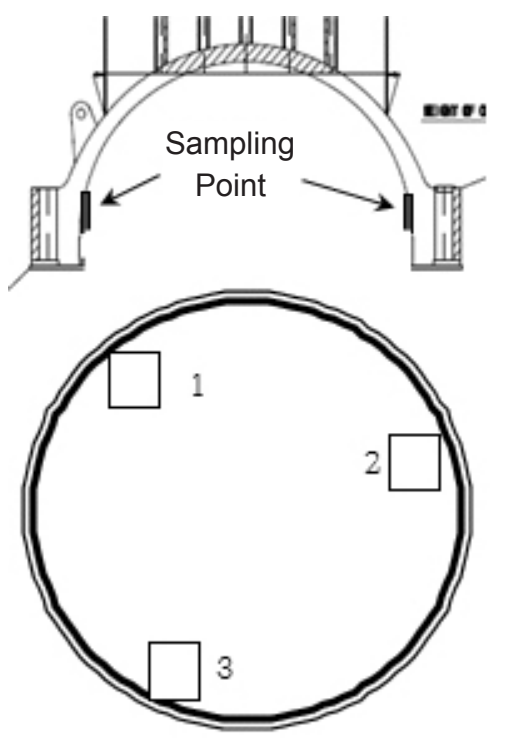

Fig. 4. Sampling point(Crud samples).

연구원에 의뢰하여 알파, 베타, 감마핵종에 대한 방사능 분 석을 수행하였다.

\section{3 원자로 헤드 모델링 및 측정}

원자로 헤드를 측정하기 전 측정장소의 바탕값(Background)을 측정하여 분석한 결과 ${ }^{40} \mathrm{~K}$ 핵종을 외의 실제 측정 에 영향을 주는 인공 핵종은 발견되지 않았고, 직접 측정을 통하여 취득한 스펙트럼을 분석할 때 기 측정한 바탕값을 제 외시키고 분석을 수행하였다.

\subsection{1 수평방향 측정 및 모델링}

원자로 헤드 수평방향 측정은 Fig. 5 와 같이 기준방향에 서 수평으로 $0^{\circ}, 45^{\circ}, 90^{\circ}$ 에서 측정하였다. 특히 원자로 헤드에 한정하여 검출기가 바라볼 수 있도록 $30^{\circ}$ 조리개를 사용하고 적정거리를 이격시켜 감마선 스펙트럼을 각 2회 측정하였다.

모델링 방법은 원자로 헤드를 Simple Cylinder Template를 사용하여 실린더 형태의 용기 하부에 원판 형태의 선원이 존재하는 형태로 Fig. 6과 같이 모델링 하였다. 용기 의 두께는 측면부위에서 차폐된 면적과 차폐되지 않은 면적 의 비를 계산하여 유효두께를 결정하였다. 수평방향 측정의 경우 3 지점의 측정 스펙트럼은 측정구조가 대칭구조이기 때

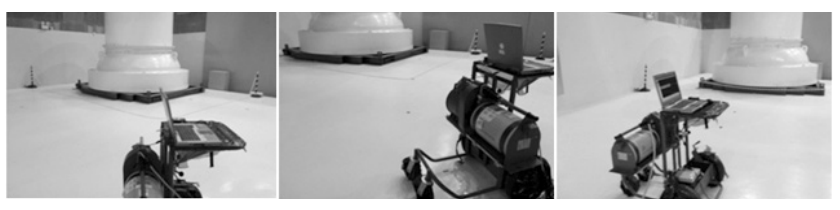

Fig. 5. Direct measurement(Horizontal G1, G2, G3).

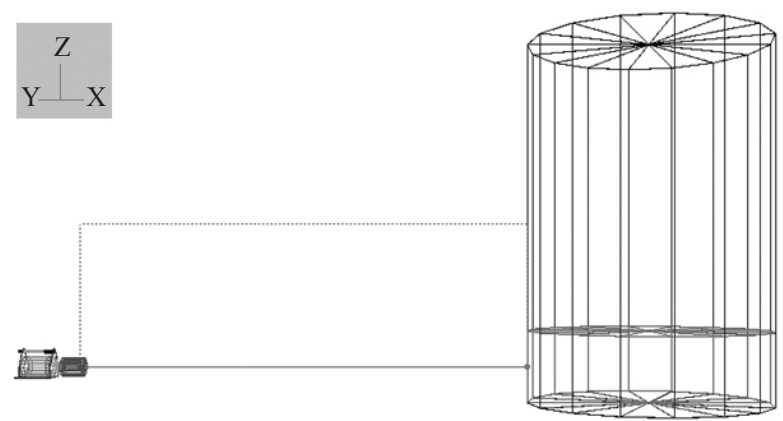

Fig. 6. Modeling for Horizontal direct measurement.

Table 2. Horizontal direction evaluation results

Ratio

(G\# Activity/Nuclides Avg)

\begin{tabular}{cccc} 
Nuclide & G1 & G2 & G3 \\
\hline${ }^{54} \mathrm{Mn}$ & 1.15 & 0.75 & 1.11 \\
\hline${ }^{58} \mathrm{Co}$ & 1.09 & 0.80 & 1.12 \\
\hline${ }^{60} \mathrm{Co}$ & 1.08 & 0.84 & 1.08 \\
\hline${ }^{65} \mathrm{Zn}$ & 1.12 & 0.90 & 0.98 \\
\hline${ }^{110 \mathrm{~m}} \mathrm{Ag}$ & 1.04 & 0.85 & 1.11 \\
\hline $\begin{array}{c}\text { Ratio } \\
(\mathrm{GH} / \mathrm{Avg})\end{array}$ & 1.08 & 0.84 & 1.08 \\
\hline
\end{tabular}

문에 동일한 효율을 적용하여 분석하였다.

수평방향 측정에 대한 방사능 평가결과 ${ }^{60} \mathrm{Co}$ 핵종의 비율이 가장 높았고, 최소검출량은 ${ }^{60} \mathrm{Co}$ 핵종을 기준으로 $1.58 \times 10^{8} \mathrm{~Bq}$ 이며, 각 측정은 $\pm 16 \%$ 이내(신뢰수준 $95 \%$ )에서 일치하는 것을 확인하였다(Table 2).

본 측정은 동일한 효율을 이용하여 평가하였기 때문에 순수하게 검출기에 입사된 계수율의 차이에 의해 측정편차 가 발생한 것이다. 따라서 원자로 헤드의 체적오염은 완전 균일하지 않음을 알 수 있으며, 이는 계통수 주입관 인접 여 부에 따라 차이가 있을 것으로 판단된다. 


\subsection{2 수직방향 측정 및 모델링}

원자로 헤드 수직방향 측정은 Fig. 7과 같이 바닥을 기준 으로 $0^{\circ}, 45^{\circ}, 90^{\circ}$ 에서 측정하였다.

모델링 방법은 $0^{\circ}$ 측정(Fig. 6)과 $45^{\circ}$ 측정(Fig. 8)의 경우 수평방향 측정의 모델링과 동일한 Template에서 ISOCS의 측정위치를 변경하여 모델링 하였다. $90^{\circ}$ 측정(Fig. 9)은 Circular Plane Template를 사용하여 수평방향 측정에서 설정 한 값과 동일하게 모델링 하였다. 용기의 두께는 차폐체의 두 께를 그대로 적용하였다.

$45^{\circ}$ 와 $90^{\circ}$ 측정의 경우 측정위치에 따라 효율이 다르기 때문에 각각의 효율을 적용하여 분석하였다.

평가결과는 수직방향과 마찬가지로 ${ }^{60} \mathrm{Co}$ 핵종의 비율이 가장 높았고, 최소검출량은 ${ }^{60} \mathrm{Co}$ 핵종을 기준으로 $1.42 \times 10^{8}$ $\mathrm{Bq}$ 이며, 각 측정은 $\pm 4 \%$ 이내 (신뢰수준 $95 \%$ )에서 일치하는 것을 확인하였다(Table 3).

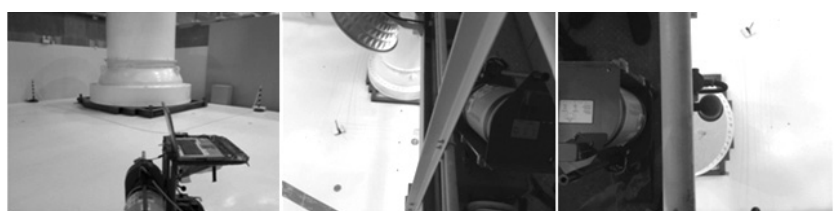

Fig. 7. Direct measurement(Vertical G1, G2, G3).

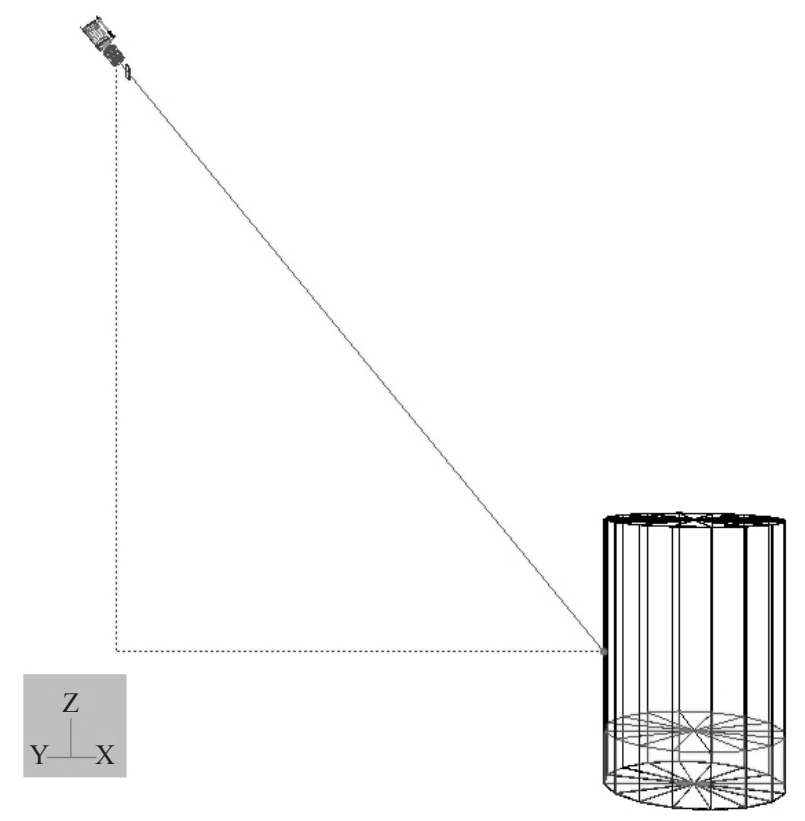

Fig. 8. Modeling for Vertical direct measurement(G2).

\section{4 측정유효성 검증}

\section{4 .1 단계 측정유효성 검증}

수평방향 측정결과와 수직방향 측정결과를 Table 4 와 같 이 상호 비교하여 1단계 측정유효성을 검증하였다.

평가 결과를 바탕으로 원자로 헤드에 대한 모델링이 적 절한 것으로 판단되고, 분석에 사용한 검출기의 계산효율이 유효함을 확인하였다.

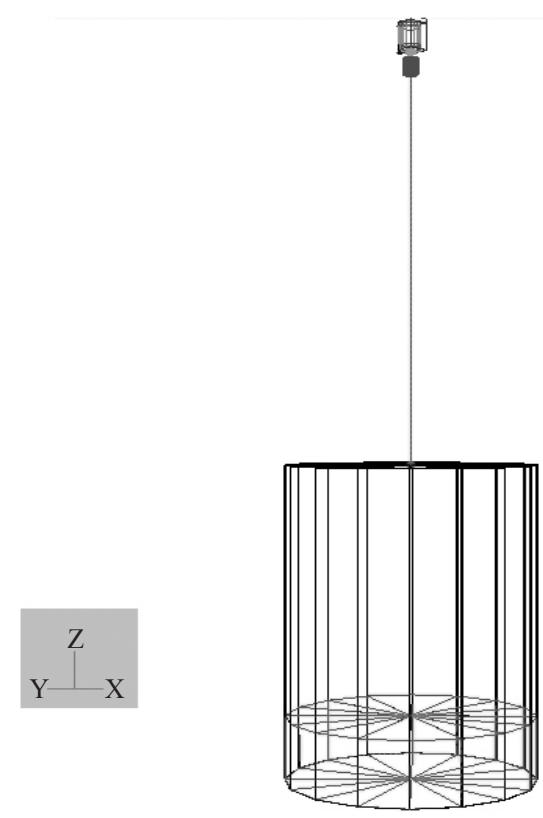

Fig. 9. Modeling for Vertical direct measurement(G3).

Table 3. Vertical direction evaluation results

\section{Ratio}

(G\# Nuclide Activity/Nuclides Avg)

\begin{tabular}{rccc} 
Nuclide & G1 & G2 & G3 \\
\hline${ }^{54} \mathrm{Mn}$ & 0.68 & 0.77 & 1.55 \\
\hline${ }^{58} \mathrm{Co}$ & 1.08 & 1.02 & 0.90 \\
\hline${ }^{60} \mathrm{Co}$ & 1.03 & 1.03 & 0.94 \\
\hline${ }^{65} \mathrm{Zn}$ & 0.07 & 1.48 & 1.18 \\
\hline${ }^{110 \mathrm{~m}} \mathrm{Ag}$ & 0.80 & 0.96 & 0.86 \\
\hline $\begin{array}{c}\text { Ratio } \\
(\mathrm{G \#} / \mathrm{Avg})\end{array}$ & 0.98 & 1.04 & 0.98 \\
\hline
\end{tabular}


Hyun Chul Jeong et al. : Assessment of the Radiological Inventory for the Reactor at Kori NPP Using In-Situ Measurement Technology

Table 4. $1^{\text {st }}$ Measurement effectiveness verification

\begin{tabular}{ccccccc}
\hline \multicolumn{7}{c}{ (G\# Nuclide Activity/Nuclides Avg) } \\
\hline \multirow{7}{*}{ Nuclide } & \multicolumn{7}{c}{ Horizontal } \\
\cline { 2 - 7 } & G1 & G2 & G3 & G1 & G2 & G3 \\
\hline${ }^{54} \mathrm{Mn}$ & 0.83 & 0.54 & 0.80 & 0.83 & 0.94 & 1.89 \\
\hline${ }^{58} \mathrm{Co}$ & 1.10 & 0.81 & 1.13 & 1.10 & 1.04 & 0.91 \\
\hline${ }^{60} \mathrm{Co}$ & 1.07 & 0.83 & 1.07 & 1.07 & 1.06 & 0.97 \\
\hline${ }^{65} \mathrm{Zn}$ & 1.03 & 0.83 & 0.90 & 1.03 & 1.25 & 1.00 \\
\hline${ }^{110 \mathrm{~m}} \mathrm{Ag}$ & 0.97 & 0.79 & 1.03 & 0.97 & 1.17 & 1.04 \\
\hline $\begin{array}{c}\mathrm{Ratio} \\
(\mathrm{G} \# / \mathrm{Avg})\end{array}$ & 1.05 & 0.82 & 1.06 & 1.05 & 1.07 & 1.00 \\
\hline
\end{tabular}

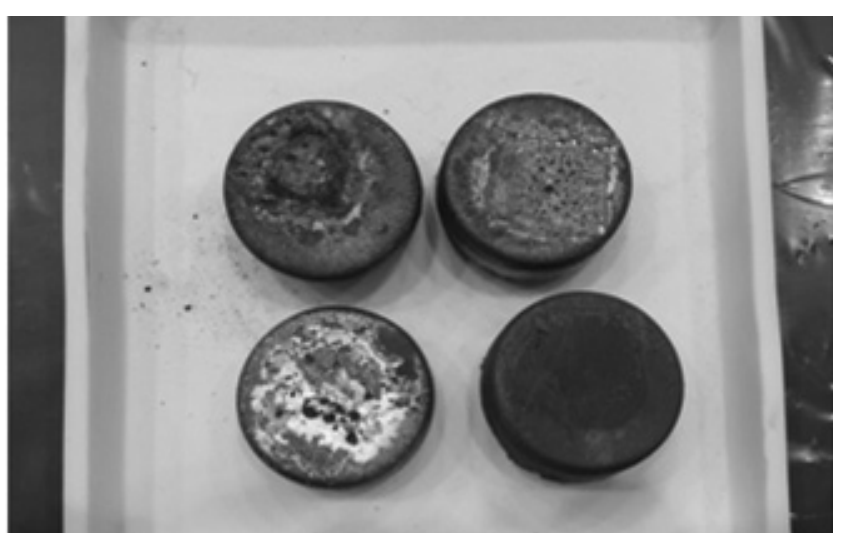

Fig. 10. Melting samples.

\subsection{2 단계 측정유효성 검증}

원자로 헤드 관통관에서 채취한 시편을 전기 용융로를 이용하여 Fig. 10과 같이 Charcoal Filter 형태로 용융하여 시 료를 가공하였다.

금속류의 밀도보정을 위해 Canberra 사의 밀도보정 상용 소프트웨어인 In-Situ Object Calibration Software를 이용하 여 밀도보정인자를 계산하여 적용시켰다.

용융시료를 측정하는 간접측정법은 비방사능으로 평가 되기 때문에 원자로 헤드의 총 방사능으로 환산하기 위해 전 체 무게를 곱하여 총 방사능량으로 환산하였다. 간접 측정결 과를 기준으로 비교한 결과 분석 값의 차이가 Table 5 와 같이 $\pm 17 \%$ 이내 (신뢰수준 95\%)에서 일치함을 확인하였다. 이 결 과로 직접 측정 분석을 위해 모델링한 검출기의 효율을 신뢰 할 수 있음을 확인하였고, 측정결과가 유효함을 확인하였다.
Table 5. $2^{\text {nd }}$ Measurement effectiveness verification

\begin{tabular}{|c|c|c|c|c|c|}
\hline & (G\# Activity/In-d & $\begin{array}{l}\text { tio } \\
\text { ct meas }\end{array}$ & ment Avg & & \\
\hline Direct & Horizont & & & Vertical & \\
\hline Measurement & G2 & G3 & G1 & G2 & G3 \\
\hline $\begin{array}{c}\text { Ratio } \\
\text { (G\#/Avg) }\end{array}$ & 0.89 & 1.15 & 1.15 & 1.17 & 1.09 \\
\hline Table 6. Radiol & sical inventory o & rud sa & & & \\
\hline & Nuclide & $\begin{array}{r}\text { (Nucl } \\
\text { Tota }\end{array}$ & $\begin{array}{l}\text { tio } \\
\text { Activity/ } \\
\text { ctivity) }\end{array}$ & $\begin{array}{r}\mathrm{F} \\
\text { (Sum } \\
\text { Total }\end{array}$ & $\begin{array}{l}\text { io } \\
\text { ctivity/ } \\
\text { tivity) }\end{array}$ \\
\hline & $\mathrm{Ag}-110 \mathrm{~m}$ & & 950 & & \\
\hline & Ce-144 & & 526 & & \\
\hline & $\mathrm{Co}-57$ & & 230 & & \\
\hline & Сo-58 & & 642 & & \\
\hline & Co-60 & & 285 & & \\
\hline & $\mathrm{Cr}-51$ & & 398 & & \\
\hline & Cs-134 & & 154 & & \\
\hline Gamma & Cs-137 & & 187 & & \\
\hline & $\mathrm{Fe}-59$ & & 093 & & \\
\hline & $\mathrm{Mn}-54$ & & 309 & & \\
\hline & $\mathrm{Nb}-94$ & & 228 & & \\
\hline & $\mathrm{Nb}-95$ & & 519 & & \\
\hline & Sb-125 & & 476 & & \\
\hline & $\mathrm{Zn}-65$ & & 714 & & \\
\hline & $\mathrm{Zr}-95$ & & 769 & & \\
\hline & $\mathrm{Fe}-55$ & & 047 & & \\
\hline & $\mathrm{Ni}-59$ & & 024 & & \\
\hline Duta & $\mathrm{Ni}-63$ & & 364 & & \\
\hline & $\mathrm{Nb}-94$ & & 000 & & \\
\hline Gross Alpha & Gross Alpha & & 003 & & 003 \\
\hline
\end{tabular}

\section{5 크러드 시료의 방사능량 평가}

원자로 헤드 내부에서 채취한 크러드 시료를 한국원자력 연구원에 의뢰하여 $\alpha, \beta, \gamma$ 핵종분석을 수행하였다. 시료 채 취 면적과 전체 접수부 면적 비를 고려하여 $\alpha, \beta, \gamma$ 핵종의 
재고량을 평가하였고, 결과는 Table 6과 같다. Table 6의 수 치는 총방사능량을 기준으로 각 핵종 방사능량의 상대비율 을 나타낸 것이다.

\section{6 원자로의 핵종재고량 평가 결과}

원자로 헤드의 체적 및 표면오염에 대한 전체 방사능량 평가를 위해 각 핵종별로 합산하였다.

원자로 헤드의 방사화가 원자로도 동일하게 방사화되었 다는 가정 하에 원자로의 핵종재고량을 계산하였다. 본 원자 로 핵종재고량 평가결과의 신뢰성을 확인하기 위해 동일 원 자로의 기존 예측결과와 비교하였으며 그 결과는 Table 7과 같다[5][6][7][8].

비교결과 In-situ 측정기술을 이용한 총방사능 평가결과 는 국내 예측결과 값 사이에 존재하여 신뢰성이 있음을 확인 하였다. 반면 해외 유사 원전의 평가결과 보다는 낮게 평가 되었다. 이와 같이, 측정결과가 예측결과보다 비교적 낮게 평가된 사유는 첫째, 코드의 경우 대부분 보수적인 조건을 이용하여 평가하기 때문이며 둘째, 본 연구의 가정인 원자로 헤드와 원자로의 방사화는 동일하다는 가정이 일부 상이한 것으로 판단된다. 하지만 원자로 헤드 측정을 이용한 원자로 전체를 평가는 충분할 것으로 판단되며 향후 수행할 원자로 선원항 정밀 예측과 상호 비교하여 본 연구의 신뢰성을 다시 한번 확인할 예정이다.

Table 7. Comparison of Reactor assessment results

\begin{tabular}{cccc}
\hline & No. & $\begin{array}{c}\text { Nuclides inventory } \\
\text { calculation method }\end{array}$ & $\begin{array}{c}\text { Vessel } \\
\text { Total Activity }\end{array}$ \\
\hline 1 & Measurement & This study & $4.40 \times 10^{11} \mathrm{~Bq}$ \\
\hline 2 & Calculation & $\begin{array}{c}\text { DORT and ORIGEN2 code } \\
\text { (KAIST) }\end{array}$ & $5.25 \times 10^{09} \mathrm{~Bq}$ \\
\hline 3 & Calculation & $\begin{array}{c}\text { MCNP/ORIGEN2 code } \\
\text { (Kyung Hee Univ.) }\end{array}$ & $4.15 \times 10^{15} \mathrm{~Bq}$ \\
\hline Note & $\begin{array}{l}\text { 1. Radioactive Inventory for typical PWR (IAEA) } \\
\text { (Italy, Trino PWR 870 MW(th), 23 years of }\end{array}$ & $3.52 \times 10^{14} \mathrm{~Bq}$ \\
& $\begin{array}{l}\text { 2. BWR Caorso } \\
\text { (Italy, 2,590 MW(th), 7 EFPY, 5 years after } \\
\text { shutdown) }\end{array}$ & $3.84 \times 10^{13} \mathrm{~Bq}$ \\
& $\begin{array}{l}\text { 3. WWER Greifswald Unit 1 } \\
\text { (Germany, 1,350 MW(th), 17 EFPY, 5 years after } \\
\text { shutdown) }\end{array}$ & $1.00 \times 10^{14} \mathrm{~Bq}$ \\
\hline
\end{tabular}

\section{3. 결론}

\section{1 원자로 헤드 선원항 평가 방법}

원자로 헤드 선원항 평가를 위해 먼저 체적오염과 표면 오염을 구분하여 평가하였다. 평가 방법은 체적오염의 경우 ISOCS를 이용하여 원자로 헤드 전체를 직접 측정하는 방법 을 사용하고, 측정의 유효성을 검증하기 위해 각 3 개의 측정 구조 별 평가 결과를 상호 비교하여 그 일치성을 확인하였 다. 또한 원자로 헤드에서 시료를 채취하여 분석한 결과를 이용하여 직접 측정결과와 비교하여 측정유효성을 다시 한 번 검증하였다.

다음으로 원자로 헤드 내부의 표면오염을 분석하기 위해 시료를 채취하여 방사화학분석을 실시하여 표면오염에 대한 방사능량을 평가하였다.

체적오염 및 표면오염의 각 핵종별 방사능량을 합산하여 원자로 헤드의 선원항을 수행하였으며 이를 통하여 원자로 전체의 핵종재고량을 평가하였다.

\section{2 선원항 평가 결과를 통한 해체 시점 결정}

원자로의 선원항 평가 결과를 이용하여 각 핵종별 경과 년 수에 따른 붕괴를 고려하여 최적의 해체시점을 결정할 수 있다.

Fig. 11 과 같이 가동 중단 초기에는 ${ }^{65} \mathrm{Zn},{ }^{54} \mathrm{Mn},{ }^{60} \mathrm{Co}$ 과

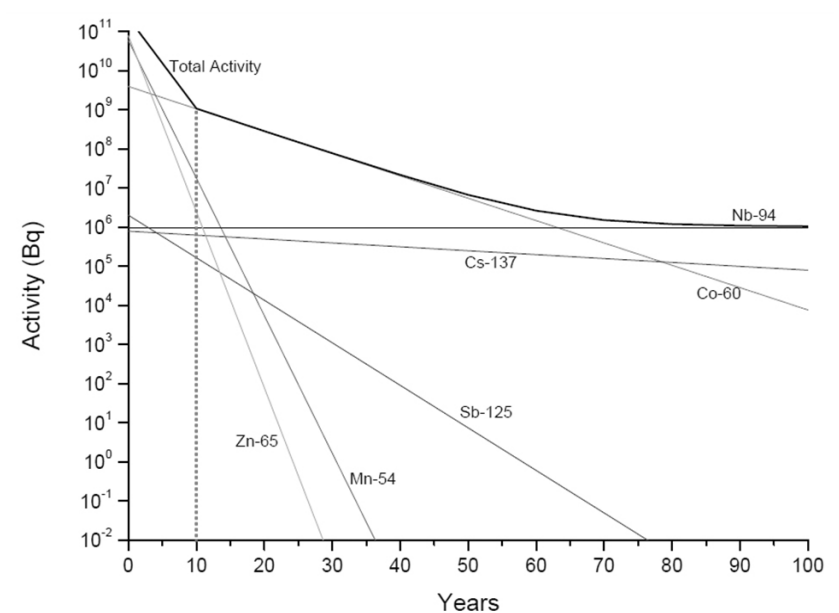

Fig. 11. Decay of calculated total activity of main nuclides in the reactor vessel. 
같은 핵종이 주요 핵종이지만 ${ }^{65} \mathrm{Zn},{ }^{54} \mathrm{Mn}$ 이 붕괴되는 비교적 짧은 시간이 즉시해체의 최적 시간으로 판단된다. 또한 지연 해체의 경우, ${ }^{94} \mathrm{Nb},{ }^{137} \mathrm{Cs}$ 핵종이 주요 핵종이 되며, ${ }^{137} \mathrm{Cs}$ 이 붕 괴되어 ${ }^{94} \mathrm{Nb}$ 핵종이 주요핵종이 되는 시점이 지연해체의 최 적 시간으로 판단되다.

\section{감사의 글}

본 연구는 [원전 해체 선원항 평가 기술 개발] 과제의 일 환으로 수행되었습니다.

\section{REFERENCES}

[1] Canberra Catalog, Canberra Industries Inc., Inspector 1000TM-based CZT Package for Nuclear Power Plant Isotope Mix Analysis(2009).

[2] Canberra Catalog, Canberra Industries Inc., Cartogam Real-Time Portable Gamma-ray Imaging System(2011).

[3] Canberra Catalog, Canberra Industries Inc., In Situ Object Counting System(2010).

[4] Davis-Besse Reactor Vessel Head Degradation Lessons-Learnde Task Force Report, September 20, 2002 "LESSONS-LEARNED FROM DAIVS-BESSE REACTOR VESSEL HEAD DEGRADATION".

[5] NKA/AO (81)8 November 1981, ENLARGED NORDIC COOPERATIVE PROGRAM ON NUCLEAR SAFETY, "NUCLIDE CONTENT IN REACTOR WASTE".

[6] Generic Environmental impact Statement for Licence Renewal of Nuclear Plants(Nureg-1437).

[7] IAEA, "Radiological characterization of shutdown nuclear reactors for decommissioning purposes", Technical Report Series No. 389(1998).

[8] H. A. Abderrahim, T. Vincent, V. Massaut, M. Klein, and R. Mandoki, "Assessment of the BR3 concrete building activation using the Tripoli Monte Carlo transport code", Radioprotection and Shielding(Proc. Top.
Mtg, Falmouth, MA, 1996), American Nuclear Society, Lagrange Park, IL(1996). 